\title{
MALIGNANT TUMORS OF ORAL CAVITY IN CHILDREN: CASES PRESENTATION
}

\author{
Bogdan POPESCU ${ }^{1,2}$, Alina L.A. OANCEA ${ }^{1,2} \bowtie$, Elena M. ARJOCA ${ }^{1}$, Roxana G. ANDRONE ${ }^{1}$, \\ Denisa M. MITRAN ${ }^{1}$, Claudiu CURCA ${ }^{1}$, Serban V.G. BERTESTEANU ${ }^{1,2}$
}

${ }^{1}$ ENT Department, Clinical Hospital Coltea, Bucharest, Romania

2 University of Medicine and Pharmacy "Carol Davila“, Bucharest, Romania

\author{
Received 23 Dec 2019, Accepted 02 Febr 2020 \\ https://doi.org/10.31688/ABMU.2020.55.1.23
}

\begin{abstract}
Introduction. Squamous cell carcinoma of the tongue is a very rare disease among children, with only a few cases reported in the literature. The tongue is the most common site for oral malignancy. The main contributing factors to pelvilingual cancer are constant irritants of the oral mucosa, such as tobacco, alcohol, and dentures. In children, however, the risk factors are immunosuppression induced by a hemopathy such as Fanconi anemia or by chemotherapy, Xeroderma Pigmentosum Syndrome or KID (keratitis, ichthyosis, deafness), Plummer-Vinson syndrome.
\end{abstract}

Cases presentations. The authors present two cases of children, 12 and 15 years old, diagnosed with pelvilingual malignant neoplasia, for which review of the clinical manifestations, the methods of diagnosis and treatment used, but also the evolution will be described.

Conclusions. Clinical symptoms of tongue cancer are similar to other types of neoplastic diseases developed in the oral cavity (for example oral floor neoplasm). Confirmation of the diagnosis is made by histopathological examination of the tissue specimen obtained from the tumor site. Therapy has a complex multimodal approach and includes, depending on staging, general condition, and the patient's option, primary and

\section{RÉsumé}

Approche des tumeurs malignes pédiatriques de la cavité orale

Introduction. Le carcinome épidermoïde de la langue est une maladie très rare chez les enfants, avec seulement quelques cas rapportés dans la littérature. La langue est l'endroit le plus commun pour la malignité buccale. Les principaux facteurs contribuant au cancer pelvi-lingue sont les irritants constants de la muqueuse buccale tels que le tabac, l'alcool et les prothèses dentaires. Chez l'enfant, cependant, les facteurs de risque sont l'immunosuppression induite par une hémopathie telle que l'anémie de Fanconi ou par la chimiothérapie, le syndrome de Xeroderma Pigmentosum ou KID (kératite, ichtyose, surdité), le syndrome de Plummer-Vinson.

Présentation du cas. Les auteurs présentent deux cas d'enfants, âgés de 12 et 15 ans, diagnostiqués avec néoplasie pelvi-lingue, pour lesquels la revue des manifestations cliniques, les méthodes de diagnostic et de traitement utilisées, mais aussi l'évolution dans le temps des patients vont être décrits.

Conclusions. Les symptômes cliniques du cancer de la langue sont similaires à d'autres types de maladies néoplasiques développées dans la cavité buccale (par 
adjuvant methods. Surgery followed by radio-, chemo-, immunotherapy are the preferred methods. Another possibility is tumor stage conversion by radio-, chemoand immunotherapeutic treatment, followed by surgery. In some cases, surgery is an ultimate method of therapy, a salvage therapy.

Keywords: pelvilingual cancer, pediatric age, surgical treatment.

\author{
List of abbreviations: \\ $\mathrm{SCC}=$ squamous cell carcinoma \\ KID $=$ keratitis, ichthyosis, deafness \\ ENT $=$ ear, nose, throat \\ $\mathrm{NBI}=$ narrow-band imaging \\ $\mathrm{MRI}=$ magnetic resonance imaging \\ OMF surgeon $=$ oral and maxillofacial surgery \\ $\mathrm{SaO} 2=$ oxygen saturation \\ BIPAP = bilevel positive airway pressure \\ FISH $=$ functional independence skills handbook \\ PET-CT $=$ positron emission tomography-computed \\ tomography \\ HPV = Human Papilloma Virus \\ TNM = tumor, lymph nodes, metastasis
}

\section{INTRODUCTION}

Squamous cell carcinoma (SCC) of the tongue is a very rare disease in children, with only a few cases reported in the literature. The tongue is the most common site for oral malignancy. It occurs more frequently in men over 45 years old, only $1.8 \%$ are under 20 years old ${ }^{1-3}$.

The main contributing factors of pelvilingual cancer are the constant irritants of the oral mucosa, such as tobacco, alcohol, and dentures. In children, however, the risk factors are the immunosuppression induced by a hemopathy such as Fanconi anemia, by chemotherapy, Xeroderma Pigmentosum Syndrome, KID (keratitis, ichthyosis, deafness) or Plummer-Vinson syndrome ${ }^{1-3}$. The clinical symptoms of lingual cancer are similar to those of other types of neoplastic diseases developed in the oral cavity (for example oral floor neoplasm).

Confirmation of the diagnosis is made by histopathological examination of the tissue specimen obtained from the tumor site. Therapy has a complex multimodal approach and includes, depending on staging, general condition, and the patient's option, primary and adjuvant methods $s^{4-6}$. Surgery followed by radio-, chemo-, immunotherapy are the preferred methods. Another possibility is tumor stage conversion by radio-, chemo- and immunotherapeutic exemple le néoplasme du plancher buccal). La confirmation du diagnostic est faite par examen histopathologique de l'échantillon de tissu obtenu à partir du site tumoral. La thérapie a une approche multimodale complexe et comprend, par rapport à la stadialisation, l'état général et l'option du patient, les méthodes primaires et advjuvantes. La chirurgie suivie de radio, chimio, immunothérapie est la méthode préférée. Une autre possibilité est la conversion du stade tumoral par un traitement radio, chimio et immuno-thérapeutique suivi d'une intervention chirurgicale. Dans certains cas, la chirurgie est une méthode ultime de thérapie, la thérapie de sauvetage.

Mots-clés: cancer pelvi-lingue, âge pédiatrique, traitement chirurgical.

treatment followed by surgery. In some cases, surgery is an ultimate method of therapy, a salvage therapy.

There is a great difference in the site of malignancy appearance in the oral cavity in children than in the adult population? Several studies tried to establish the incidence and prevalence of squamous cell carcinoma in the young population but failed to obtain a pertinent conclusion. It is considered that the occurrence of malignancies of the oral cavity in patients under 30 years of age is extremely rare, with 1 in 1000 patients $^{8,9}$. Squamous cell carcinoma in pediatric patients has only been reported in isolated cases, with no overall data in incidence, evolution, and prognosis ${ }^{10-12}$.

The authors present two cases of children, 12 and 15 years old, diagnosed with pelvilingual malignant neoplasia, for which the review of the clinical manifestations, the methods of diagnosis and treatment used, but also the evolution in time of the patients will be described. These patients were treated in pediatric oncology departments and therapy was conducted by the oncologist. Surgery was performed by the authors in specialized ENT departments with oncology setup.

\section{FiRST CASE PRESENTATION}

A female patient, 12 years old, presents to the ENT Clinic of "Marie Curie" Emergency Children's 
Hospital, Bucharest, Romania, in February 2018 for dysphagia, odynophagia and the occurrence of a vegetative tumor of the free right margin of the tongue, extended to the oral floor. The patient and family affirmed that the symptoms' onset was 2 weeks before presentation at the ENT specialist.

Clinical examination of the head and neck region revealed a vegetative tumor on the free right margin of the tongue, extended to the oral floor on the right side, which did not affect the mobility of the tongue, and a right latero-cervical tumoral mass, consistent for a lymphadenopathy at levels II and III, with hard consistency, immobile on the superficial and deep layers of the neck, painless and without inflammatory phenomena.

The fibrescopic examination revealed adenoid vegetation bundle on the upper wall, occupying $1 / 3$ of the volume of the rhinopharynx, without obstruction on the Eustachian tube, orifices, normotrophic palatine tonsils, base of the tongue moderately hypertrophic without clinical appearance of malignancy (with the aid of color-specific fibrescope using the NBI-function filter) and a normal larynx.

An MRI of the head and neck regions was performed with contrast and revealed an area with a non-homogeneous "horseshoe" shape in the transverse plane, opened to the posterior region of the horizontal

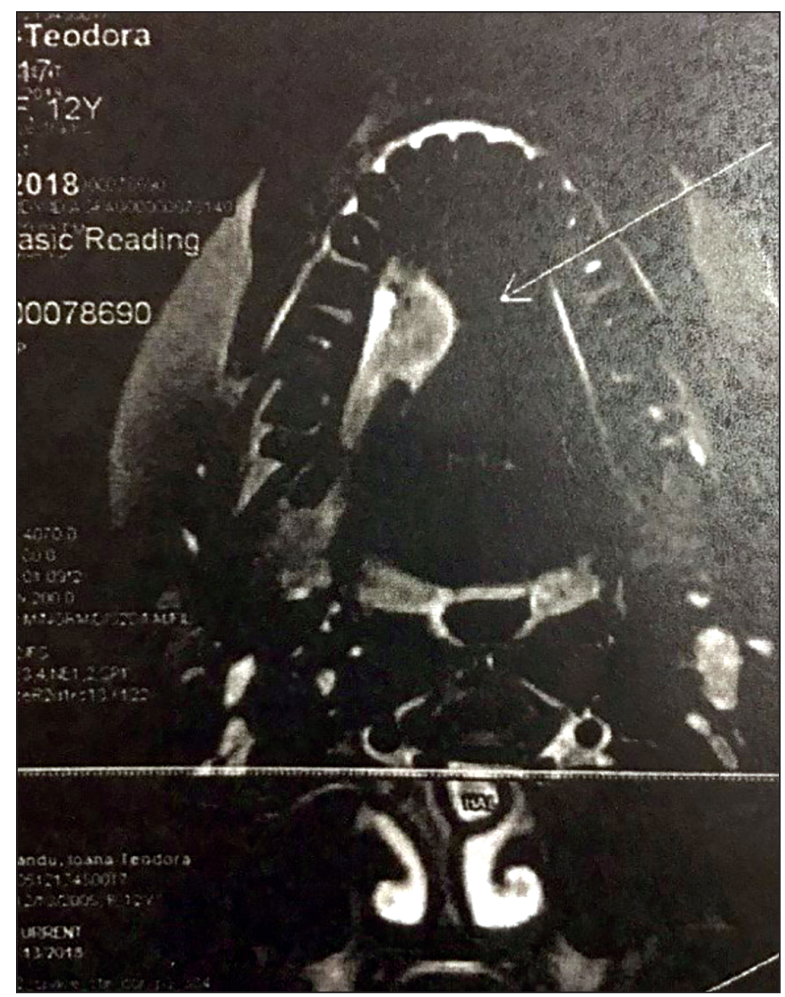

Figure 1. Transverse section in 1,5 Tesla MRI with contrast showing the tumor mass on the free right side of the tongue. portion of the mandible, without infiltration of the bone or the periosteum (Figure 1). Lymph nodes were expressed in the right latero-cervical region adjacent to the upper portion of the internal jugular vein, no more than $2 \mathrm{~cm}$ in the greatest diameter.

Laboratory tests were normal. An incision biopsy was taken to establish the nature of the tumor. Histopathological examination of the right pelvilingual tumor revealed the diagnosis of non-invasive squamous cell carcinoma G1, well-differentiated subtype. The data were analyzed and discussed in The Oncology Committee. The therapy plan was set to be radical surgery with curative intent, followed by radiotherapy, depending on the post-operative results of the tumor specimen and resection margins. The oncology team was formed of the ENT surgeon, anesthesiologist, nutrition therapist, OMF surgeon, plastic surgeon, oncologist, radiotherapist, and psychologist. The mixed surgical team was formed of an ENT surgeon, OMF surgeon and plastic surgeon. A classical approach was preferred due to the anatomy of the region and the extent of the tumor, along with the absence of $\mathrm{CO}_{2}$ LASER. The surgery was performed under general anesthesia and oral-tracheal intubation. A temporary tracheostomy was performed, along with right functional neck dissection and histopathological examination. The resection of the tumor was performed trans-orally and the resection specimen included anterior and right $2 / 3$ of the oral tongue and buccal floor. Intraoperative examination revealed that the mandible was not infiltrated. A nasogastric feeding tube was placed. Antero-lateral free myo-cutaneous flap from the left thigh was raised and micro surgically anastomosed to the lingual vessels and hypoglossal nerve to reconstruct the defect of the oral cavity.

Postoperative histopathological examination revealed the diagnosis of well-differentiated squamous cell carcinoma of the tongue and out of the twelve lymph nodes excised after neck dissection only one lymph node was detected with metastasis.

The postoperative evolution was slowly favorable, initially with enteral feeding exclusively on the nasal gastric tube for 14 days, then mixed for another 14 days and oral feeding afterward, when the tube was suppressed. The local evolution was favorable, the suture material was removed 14 days post-surgery. The follow-up showed a clean and completely healed incision site and fully integrated, viable myo-cutaneous flap.

The patient underwent adjuvant therapy onemonth post-surgery with 33 cures of radiotherapy and 6 cycles of chemotherapy with a favorable evolution. At 11 months post-surgery the patient's tracheostomy was removed (Figure 2). 


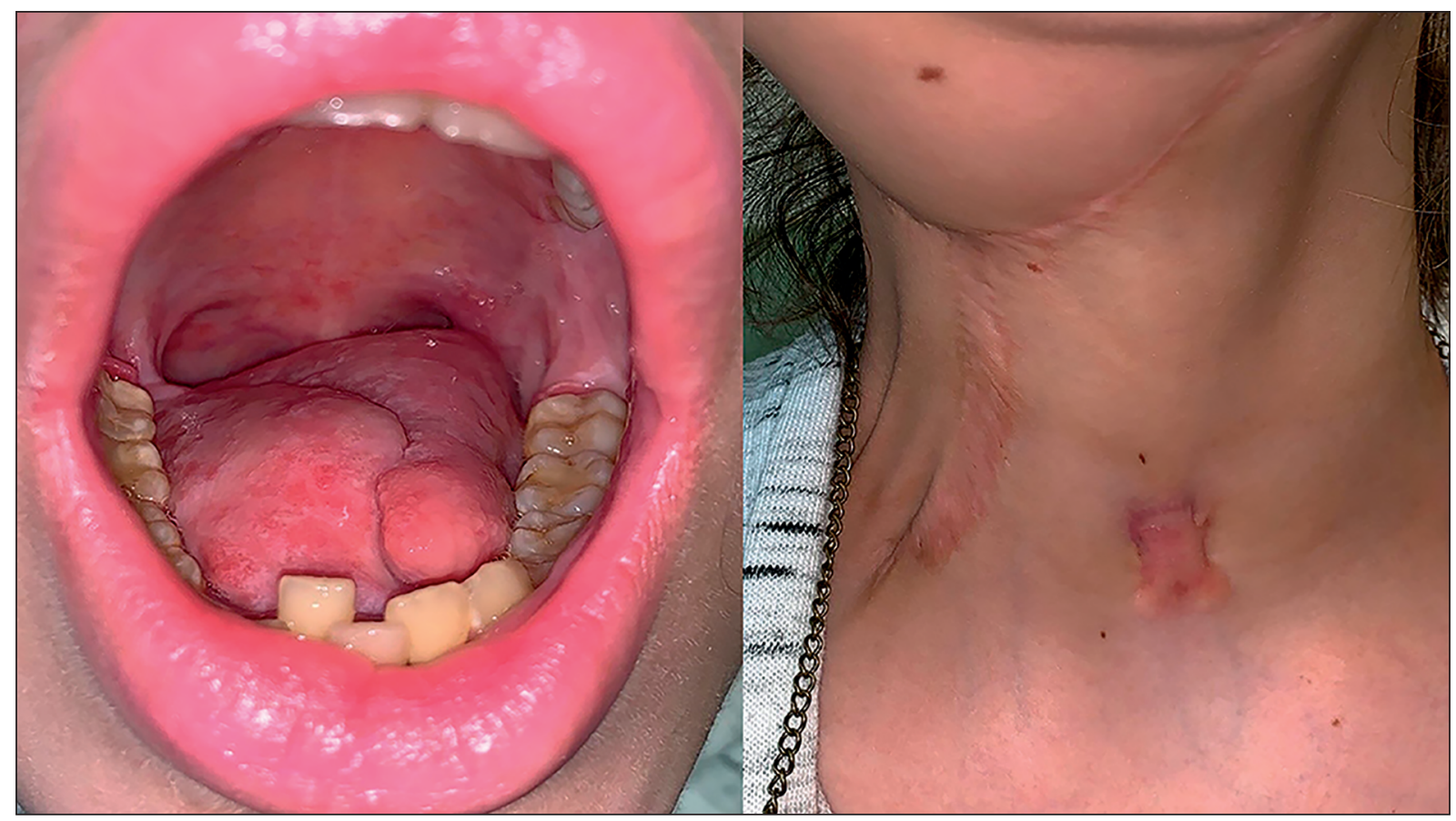

Figure 2. Intraoral and cervical aspect at 15 months post-surgery.

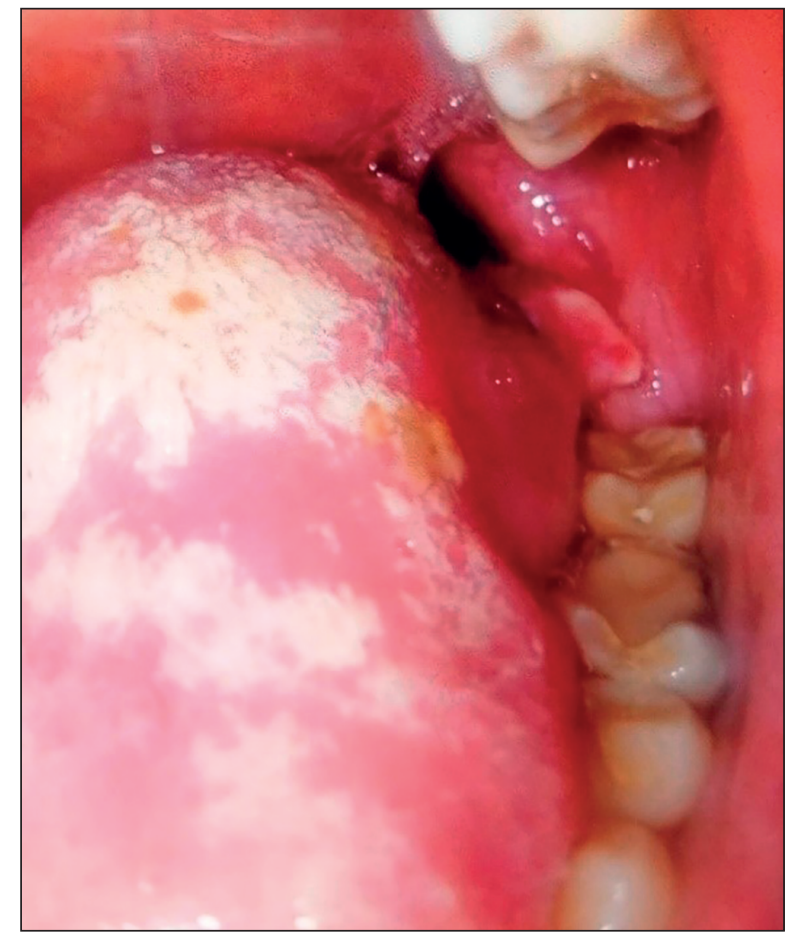

Figure 3. Primary tumor at the beginning of the symptoms. Vegetative tumor arising from the oral tongue, floor of the mouth and retromolar region.

\section{Second case PResentation}

A male patient, 15 years old, from rural environment, presented in September 2018 to the Pediatric Oncology Department of "Grigore Alexandrescu"
Emergency Hospital for Children, Bucharest, Romania, for oral bleeding from a vegetative tumor arising from the oral tongue, the floor of the mouth and retromolar region. The tumor had been evolving for the last 4 months and was treated with antibiotics and non-steroid anti-inflammatory drugs in the dentist's office (Figure 3).

An emergency evaluation was performed because the patient was intubated with mechanic ventilation and was bleeding from the tumor. No prior biopsy was performed. CT scan revealed a hetero-dense area with fluid, para-fluid and diffuse tissue densities, delimited by a discrete iodophilia of the enlarged tissue component, affecting $2 / 3$ of posterolateral tongue, oro and hypopharynx with predominantly deformation of the left vallecula, without excluding a possible extension to the palatine region. External carotid diagnostic angiography revealed the right external carotid artery, branches adjacent to the tongue and the common right carotid artery with normal appearance. Emergency procedures were performed and a tracheostomy was made, with subsequent tracheal ventilation. A biopsy sample was taken. Histopathological examination revealed a vascular tumor with intermediate malignancy, possibly a Kaposi-form haemangioendothelioma, and immunohistochemical tests were required.

The clinical examination performed in the Intensive Care Unit revealed unconsciousness, uncooperative, fever $\left(39.9^{\circ} \mathrm{C}\right)$, pale skin and mucous membranes, $\mathrm{SaO}_{2} 96 \%$. The continuous bleeding led 


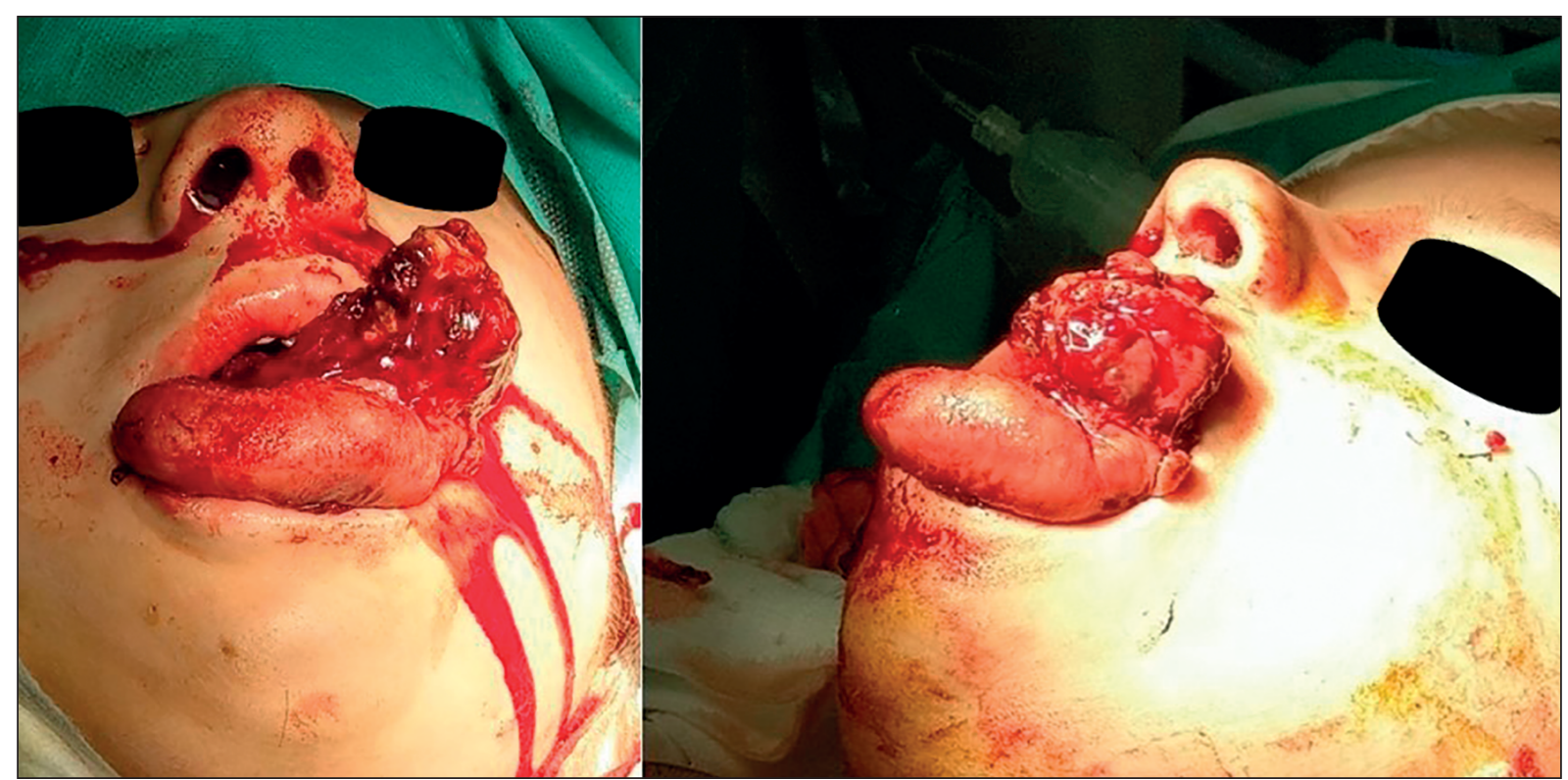

Figure 4, 5. Preoperative aspect of the exteriorized oral cavity tumor.

Exteriorized tumoral mass of the oral cavity, vegetative with areas of necrosis and bleeding.

to the decision of tamponing the oral cavity and nasopharynx, respectively the initiation of mechanical ventilation by the BIPAP system.

CT scans were re-evaluated, with the description of a bulky space replacing process at the level of the oral cavity, which included the entire tongue, floor of the mouth, oro- and nasopharynx and inferior extension to the upper part of the trachea. The tumoral mass was imprecisely delimited, non-homogeneous, with a predominantly tissue component, presenting areas of necrosis and bleeding. Significant left latero-cervical edema, comprising the subcutaneous muscular plane and left parotid gland, with a mass effect on the left jugular-carotid vascular bundle, was also observed. The patient's condition remained critical (Figure 4, 5).

After analyzing the therapy options and morbidities, the decision for surgery was made and the parents were informed so they could consent to surgery. After both parents signed the informed consent, the oncological surgery team prepared the patient for an emergency procedure combined with the radical oncological surgery. The aims were to remove the tumoral mass and its neck metastasis with safe oncological margins, to stop the bleeding, to decrease the risk of septicemia, to ensure a proper feeding pathway, because the patient had total parenteral nutrition for 6 days, and to ensure the functionality of the oral cavity as much as possible. Surgery included de-tamponing the oral cavity, bilateral external carotid artery ligation because the tumor surpassed the midline of the tongue, transoral resection of the tumor with safe oncology margins and functional bilateral neck dissection. All the resection samples were sent for histopathological examination (Figure $6,7,8)$.

Postoperative evolution was favorable, the patient is conscious, cooperative, without bleeding and was fed through the nasogastric tube. Enteral feeding via nasogastric tube was kept for 21 days and the nutritional status of the patient improved significantly. No bleeding or signs of infection were present postoperatively. The drain tubes and suture material were removed 5, respectively 12 days after surgery.

Immunohistochemical aspects suggested a malignant tumor proliferation with small, round, blue cells, 85\% positive for Ewing $\mathrm{Ki}$ sarcoma. The final pathological result was malignant small-cell tumor proliferation (CD99 with Ki 67 positive in approximately $85 \%$ of the tumor cells), most likely Ewing's sarcoma \PNET extra-skeletal. Genetic testing was performed. The FISH assessment did not reveal Ewing's sarcoma-specific EWSR (22q12) rearrangement. After all the tests were performed, the diagnosis could not be confirmed with certainty.

Chemotherapy was started one month after surgery, because surgical healing was great. After the $5^{\text {th }}$ series of chemotherapy, at the head and neck MRI reassessment, no signs of local recurrence were revealed. There were no detectable metabolically active lesions at the PET-CT scan either.

The patient had the tracheostomy removed one year after the oncological therapy concluded. Follow-up is performed by clinical and pan-endoscopic examination every 2 months for the first 2 years and PET-CT annually. 


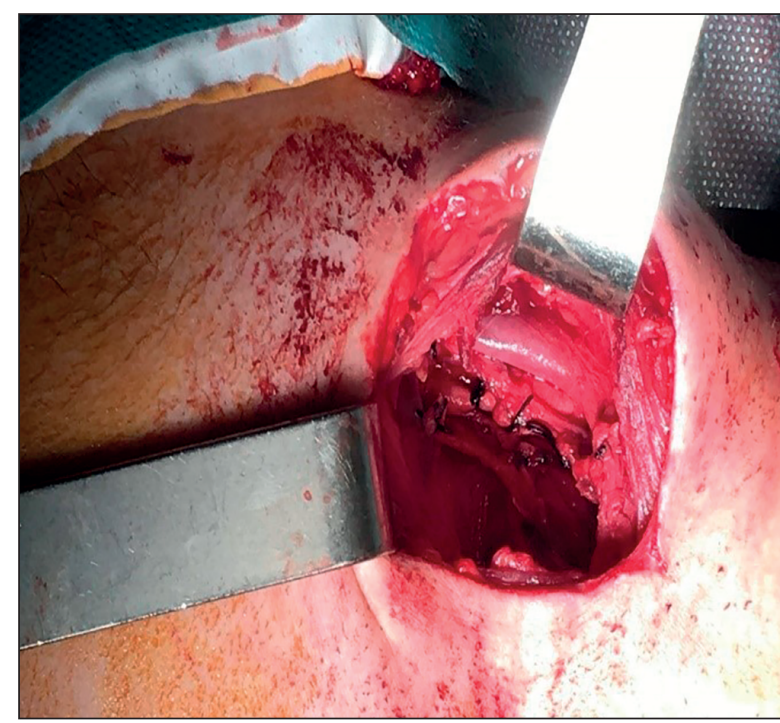

Figure 6. Functional neck dissection and external carotid artery ligation on the left side of the neck.

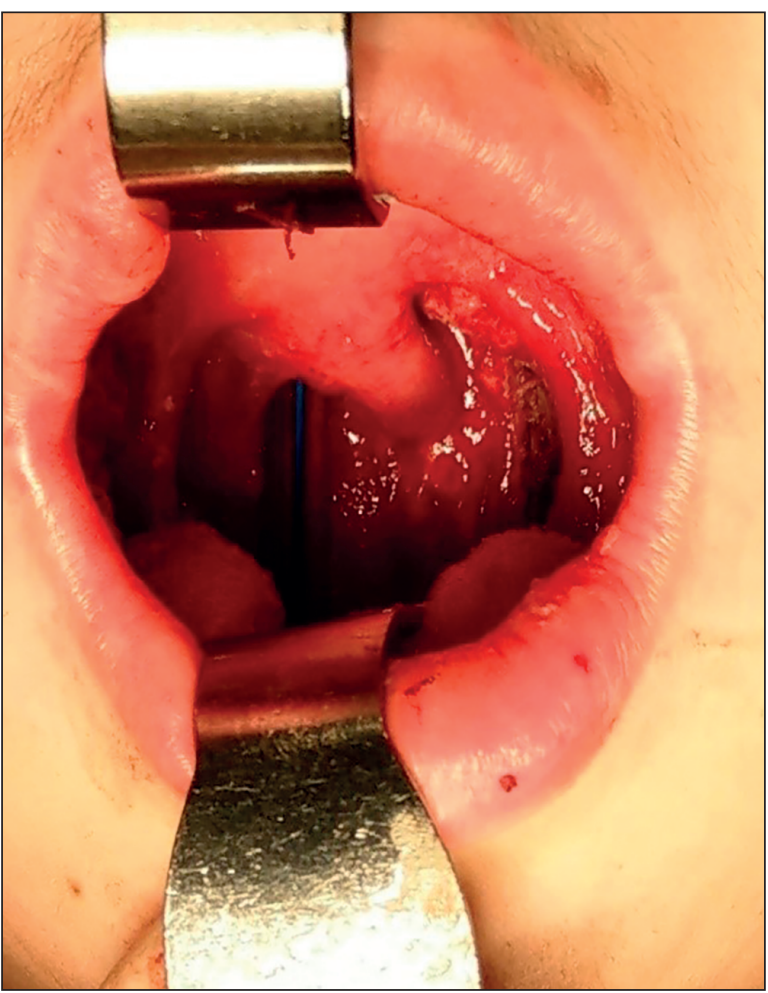

Figure 8. Intraoperative aspect after the tumor was removed and the reconstruction of the tongue and floor of the mouth were performed.

\section{Discussion}

The etiology of SCC in pediatric patients is considered to be distinct from that of the adults. However, there are contradictory data in the literature regarding these aspects in terms of alcohol and tobacco consumption ${ }^{3,13}$. Since there are no consistent

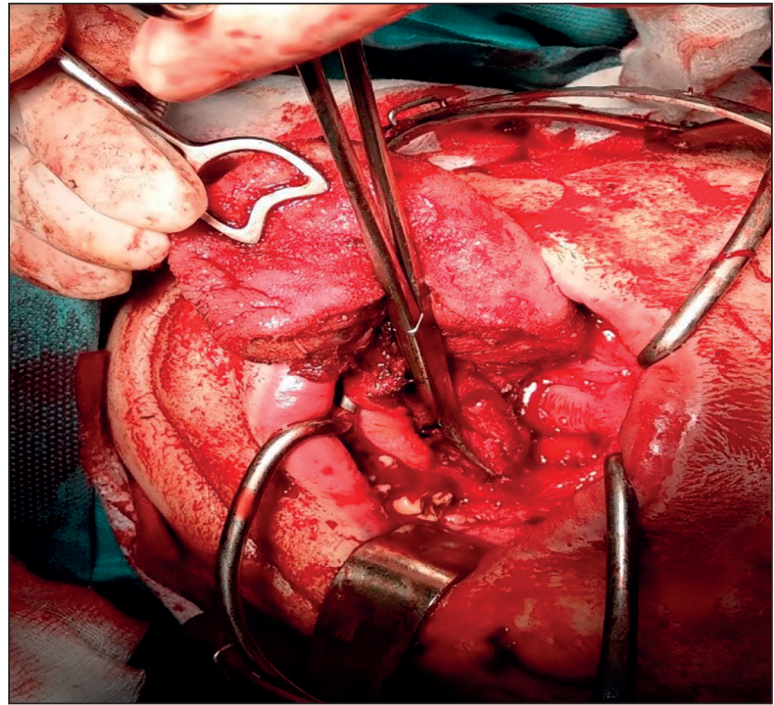

Figure 7. Transoral resection of the tongue, floor of the mouth and retromolar region.

data in the literature regarding the etiology, it is hard to believe that tobacco and alcohol consumption are the same in pediatric and adult life ${ }^{14,15}$. There is still the question of genetic susceptibility in the interaction with different etiological factors, such as Fanconi anemia, Xeroderma Pigmentosum, keratosis-ichthyosis-deafness (KID) syndrome and other unidentified genetic conditions susceptible to associate malignant neoplasia of the oral cavity ${ }^{16-18}$. Luc et al, in a study over two cohorts, 10 pediatric patients and 40 adult patients, found that tobacco use history, TNM status, surgical procedure, adjuvant radiotherapy, overall survival, disease-specific survival, and recurrence-free survival were similar when comparing the two ${ }^{19}$.

Anatomical and clinical onset forms of oral malignancies are red spots and hypertrophic white spots or blotchy leukoplakia which constitute the clinical aspect of leucoplasia to erythroplasia, and carcinoma in situ. After the rupture of the basal membrane, the lesions evolve towards invasive carcinoma. The ulcerative form has a useful element in the orientation of the diagnosis in the aspect of the bottom of the ulceration, a granular aspect is a sign of malignancy. The lesions are most often painless initially, the subsequent pain being associated with their over-infection, the patient's presentation to the doctor being relatively late. In the vegetative form, the lesions are prominent, buds with vegetative appearance, the surface of the lesion is engraved with ulcerative appearance, covered by fibrous deposits that bleed spontaneously or on palpation.

In evolution, the lesion base became hardened, with diffuse infiltration and fixation, the perilesional area being congested and swollen. A particular aspect 
of malignant tumors of the oral cavity is "the versatility". Oral malignancies invade closely to the adjacent structures, so, during evolution, it is sometimes difficult to determine the starting point.

Differential diagnosis of the buccal and tongue tumoral masses is made with ulcerations (traumatic, chemical, thermal), syphilis, HPV, tuberculosis, contact allergy, leukoplakia and chronic candidiasis.

Oncological surgery with curative intent has the possible advantage of disease-free survival and prolonged survival rates in comparison to radiotherapy. However, surgery in the head and neck region has the downside of functional and aesthetic impairment. Depending on the stage of the malignancy, different approaches are to be considered. Some of them imply the need for facial and/or cervical scaring which can alter the quality of life. Considering the occurrence of the pathology in the early years of life and young adulthood, we can assume there is a great impact on the relational status with community members. Therefore, there is the need to put in balance the extensiveness of surgery with radical intent and the impact on each patient. The decision for therapy is to be made by legal guardians in pediatric patients. Another aspect that needs to be put into perspective is the functionality of deglutition, speech, and breathing. The presence of a tracheostomy decreases the quality of life for these patients, especially the young ones. Surgery of the oral cavity tends to alter the voice and impair speech, which can result in communication difficulties and, in some cases, social alienation. Psychological support is always a must for both children and parents.

It is important to discuss each case individually in The Oncology Committee and to establish the best possible course of action in terms of oncology therapy, this being a multimodal effort ${ }^{19}$.

\section{Conclusions}

Any symptoms without a precise etiology or the presence of an oral lesion that does not fit into the normal general clinical status, constitutes an alarm signal for raising the suspicion of a tumor. Persistent ulceration after therapy, leukoplakia as a premalignant lesion or swelling without an obvious cause, are situations in which the suspicion of cancer should be present. Age is not a factor for the appearance of malignant neoplasia since there is an alarming decrease in the lower limit of age for the onset of malignancies.

Because symptoms and signs of malignant neoplasia of the oral cavity are not specific and oral cancer in children occurs with a low frequency, the diagnosis is made in late stages. However, some cases present to the specialist in an early stage, with better prognosis and fewer functional impairment after oncological therapy. Some authors consider that aggressive disease with poor prognosis is not the case in the pediatric population. However, these findings are based on small cohorts. Also, therapy options should be the same as in the adult population with oral malignancies ${ }^{20}$. Oncological therapy should be considered individually and each case should be discussed in The Oncology Committee. From our standpoint, the best oncological approach is surgery followed by radiotherapy for squamous cell carcinoma depending on staging, morbidities, and preference of the child's legal advisor.

\section{Author contributions}

B.P., A.L.A.O. and S.V.G.B. were responsible for the diagnostic procedures, clinical diagnosis and treatment decisions. B.P. performed the surgery. E.M.A., D.M.M., C.C. and R.G.A. wrote the manuscript. All authors have read and agreed to the published version of the manuscript.

\section{Compliance with Ethics Requirements:}

„The authors declare no conflict of interest regarding this article"

„The authors declare that all the procedures and experiments of this study respect the ethical standards in the Helsinki Declaration of 1975, as revised in 2008(5), as well as the national law. Informed consent was obtained from all the patients included in the study"

"No funding for this research"

\section{Acknowledgments: none}

\section{References}

1. de Carvalho M, Sobrinho Jde A, Rapoport A, et al. Head and neck squamous cell carcinoma in childhood. Medical and Pediatric Oncology. 1998;31(2):96-99.

2. Llewellyn C, Johnson N, Warnakulasuriya K. Risk factors for squamous cell carcinoma of the oral cavity in young people--a comprehensive literature review. Oral Oncology. 2001;37(5):401-418.

3. McDowell J. An overview of epidemiology and common risk factors for oral squamous cell carcinoma. Otolaryngologic Clinics of North America. 2006;39(2):277-294.

4. Ciuhu AN, Rahnea Nita RA, Popescu M, et al Evidence of strong opioid therapy for palliation of breathlesness in cancer patients. Farmacia. 2017;65(2):173-178.

5. Tiglis M, Neagu TP, Elfara M, et al. Nefopam and its role in modulating acute and chronic pain. Rev Chim (Bucharest). 2018;69(10):2877-2880.

6. Dumitru N, Cocolos A, Caragheorgheopol A, et al. Collagen - the ultrastructural element of the bone matrix. Rev Chim (Bucharest). 2018;69(7):1706-1709. 
7. Funk G, Karnell L, Robinson R, Zhen W, Trask D, Hoffman H. Presentation, treatment, and outcome of oral cavity cancer: a National Cancer Data Base report. Head $\mathcal{E}$ Neck. 2002;24(2):165-180.

8. Sidell D, Nabili V, Lai C, Cheung G, Kirsch C, Abemayor E. Pediatric squamous cell carcinoma: Case report and literature review. The Laryngoscope. 2009;119(8):1538-1541.

9. Llewellyn C, Linklater K, Bell J, Johnson N, Warnakulasuriya $\mathrm{S}$. An analysis of risk factors for oral cancer in young people: a case-control study. Oral Oncology. 2004;40(3):304-313.

10. Soni S, Radel E, Smith R, et al. Stage 4 squamous cell carcinoma of the tongue in a child: complete response to chemoradiotherapy. Journal of Pediatric Hematology/Oncology. 2001;23(9):612-615.

11. Reinhard H, Peters I, Gottschling S, Ebell W, Graf N. Squamous cell carcinoma of the tongue in a 13-year-old girl with Fanconi anemia. Journal of Pediatric Hematology/ Oncology. 2007;29(7):488-91.

12. Earle A, Park C, Vlastou C. Oral squamous cell carcinoma in children. Annals of Plastic Surgery. 1988; 20(2):148-152.

13. Blot W, McLaughlin J, Winn D, et al. Smoking and drinking in relation to oral and pharyngeal cancer. Cancer Research. 1988;44(11):3282-3287.

14. Diaconu C, Nastasa A, Zaki AR, Arsalan M. Type 2 diabetes: a driver for chronic heart failure. The $2^{\text {nd }}$ International
Conference on Interdisciplinary Management of Diabetes Mellitus and its Complications - Diabetes mellitus as cardiovascular disease, INTERDIAB 2016 Proceedings, pp. 201-210. Ed. Niculescu. Editors Serafinceanu C, Negoita O, Elian V.

15. Diaconu C, Balaceanu A, Ghinescu M. A neck mass that disapears at compression: is it a reason for concern? Acta Medica Mediterranea. 2015;31(2):339-341.

16. Byers R. Squamous cell carcinoma of the oral tongue in patients less than thirty years of age. American Journal of Surgery. 1975;130(4):475-478.

17. Bucur D, Berceanu D, Diaconu C. Hemostasis in patients with cirrhosis: a hazardous balance. Arch Balk Med Union. 2016;51(4):501-505.

18. Diaconu C. Atrial septal defect in an elderly woman - a case report. Journal of Medicine and Life. 2011;4(1):91-93.

19. Zhang H, Dziegielewski P, Biron V, et al. Survival outcomes of patients with advanced oral cavity squamous cell carcinoma treated with multimodal therapy: a multi-institutional analysis. Journal of Otolaryngology - Head $\mathcal{E}$ Neck Surgery. 2013;42(1):30.

20. Morris L, Patel S, Shah J, Ganly I. Squamous cell carcinoma of the oral tongue in the pediatric age group: a matched-pair analysis of survival. Archives of Otolaryngology-Head $\mathcal{E}$ Neck Surgery. 2010;136(7):697-701. 